\title{
THE EFFECT OF PHOTOVOLTAIC LOCATION ON POWER QUALITY OF THE UTILITY GRID
}

\author{
Mariem Yakoub Youssef , Mohamed Mahmoud Ismail and Said Mohamed El masry \\ Faculty of Engineering Helwan University, Electrical Power and Machine Department \\ Cairo, Egypt
}

\begin{abstract}
Recently, the applications of solar energy to generate electric power using photovoltaic, PV is increasing rapidly, to improve the utilization of this system a power electronic converters are needed, whoever these power electronic devices inject harmonic current into the grid consequently deteriorate the quality of electric power. This paper studies the effect of PV system location and PV penetration level on the harmonic content at the point of common coupling and on the other power grid buses. The study will be conducted by integrated different rating of PV system with the nine-bus IEEE system at different location to determine the best location and penetration level in order to minimize the total harmonic distortion. The system modelling and simulations are carried out using MATLAB platform.
\end{abstract}

\section{KEYWORDS: PV System, IEEE 9 bus grid, THD and best location}

\section{INTRODUCTION}

Renewable energy is the energy that comes from resources, which are continually replenished such as sunlight, wind, tides, waves and geothermal energy. Every day, the sun radiates an enormous amount of energy called solar energy. Solar energy falls on the surface of the earth at a rate of 120 beta watts. This means solar energy received from the sun in one-day can satisfied the whole world's demand for more than 20 years.

Photovoltaic cells are devices used to convert solar energy to electrical energy by means of semiconductor materials. Solar power is often regarded as one of the most promising energy sources for the future, but it is today one of the most expensive sources, due to high investment costs. However, the price has steadily decreased and in some countries, grid connected PV systems are economically feasible. In places with a high solar radiation and a weak existing power grid, specifically for off-grid locations, solar power is regarded as a costeffective solution [1].

The deregulation of electricity markets and requirement to reduce greenhouse gas emission from the conventional electric power generation make the distributed generation (DG) renewable energy systems gain a great opportunity as a new means of power generation that meet the accelerated demand for electric energy [2.3].

Among all the various DG technologies, PV systems are rapidly growing in electricity markets due to the declining cost of PV modules [4, 5], increasing efficiency of PV cells, manufacturing-technology enhancements and economics of scale. However, increasing penetration levels of PV systems into the grid have given rise to potential problems relating to power quality and PV performance [6-8].

One of the most important applications of photovoltaic (PV) standalone systems is for rural areas that have a considerable amount of solar radiation and no access to national grids [9]. The performance of PV system is affected due to the amount of sun radiation [10]. 
However, the connection of large scale PV systems to grid will cause several problems in power quality, these problems depends on percentage of PV penetration levels such as inrush current, over voltage, output power fluctuation, frequency fluctuation and harmonics.

One of the previous research was focus on finding the most sensitive node in IEEE- 14 bus systems according to voltage stability by step loading increase, [11]. Many techniques are used to study the power quality of PV grid connected system [12-16], while none of the previous researches studies the effect of PV array location on the power quality.

In this paper PV system with different level of penetration will be connected at different location of the IEEE- 9 bus system to find the best location according to the total harmonic distortion at different penetration levels.

\section{The System Model}

In order to determine the best location to connect PV plant to the IEEE - 9 bus system, the system model including PV system should be developed.

\section{A. PV SYSTEM MODEL}

The PV system used is composed of number of subfield each subfield is $500 \mathrm{KW}$. The subfield system under study is shown in Figure 1. The output of the subfield array is connected to a boost DC converter that is used to perform MPPT functions and increase the array terminal voltage, then the output voltage connected to voltage source inverter to convert $\mathrm{DC}$ voltage to $\mathrm{AC}$ voltage. Finally connect the output voltage from the inverter to step up transformer to match the value of distribution system grid at $230 \mathrm{kV}$. Multi-Inverter plant layout is used in large size plants where it is divided into subfields. PV subfield system is modeled using number of sun power SPR-305-WHT modules. The array consists of 164 strings of 10 series modules connected in parallel. Each module has 96 cell connected in series. The electrical datasheet for one module is given in the appendix.

\section{B. The Grid Model}

In order to determine the best location to connect PV plant to the IEEE - 9 bus system, schematic diagram for the IEEE-9 bus is prepared as shown in Figure 2 and power flow study has been carried out firstly. Second, the IEEE - 9 bus system with PV system connected on the three load buses 5, 6, 8 has been carried out three times, one time for each bus.

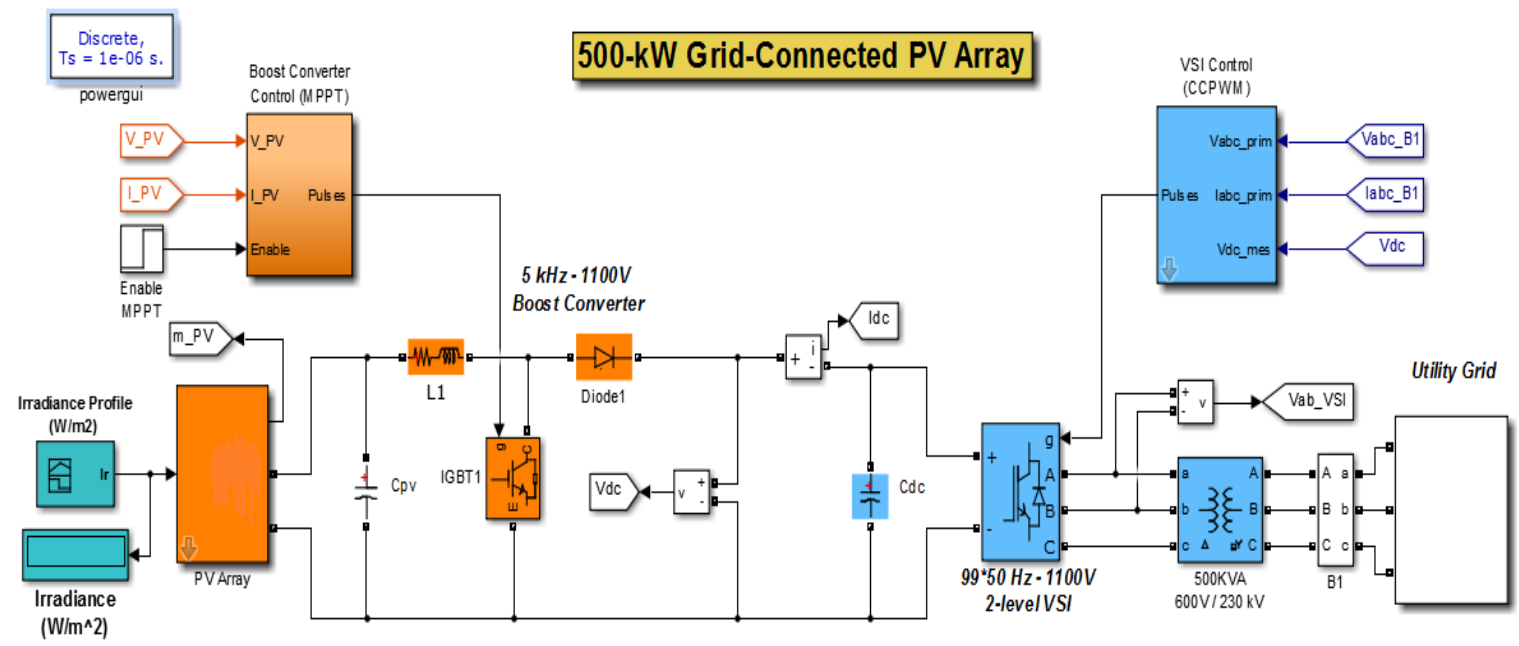

Fig (1) - PV subfield model 


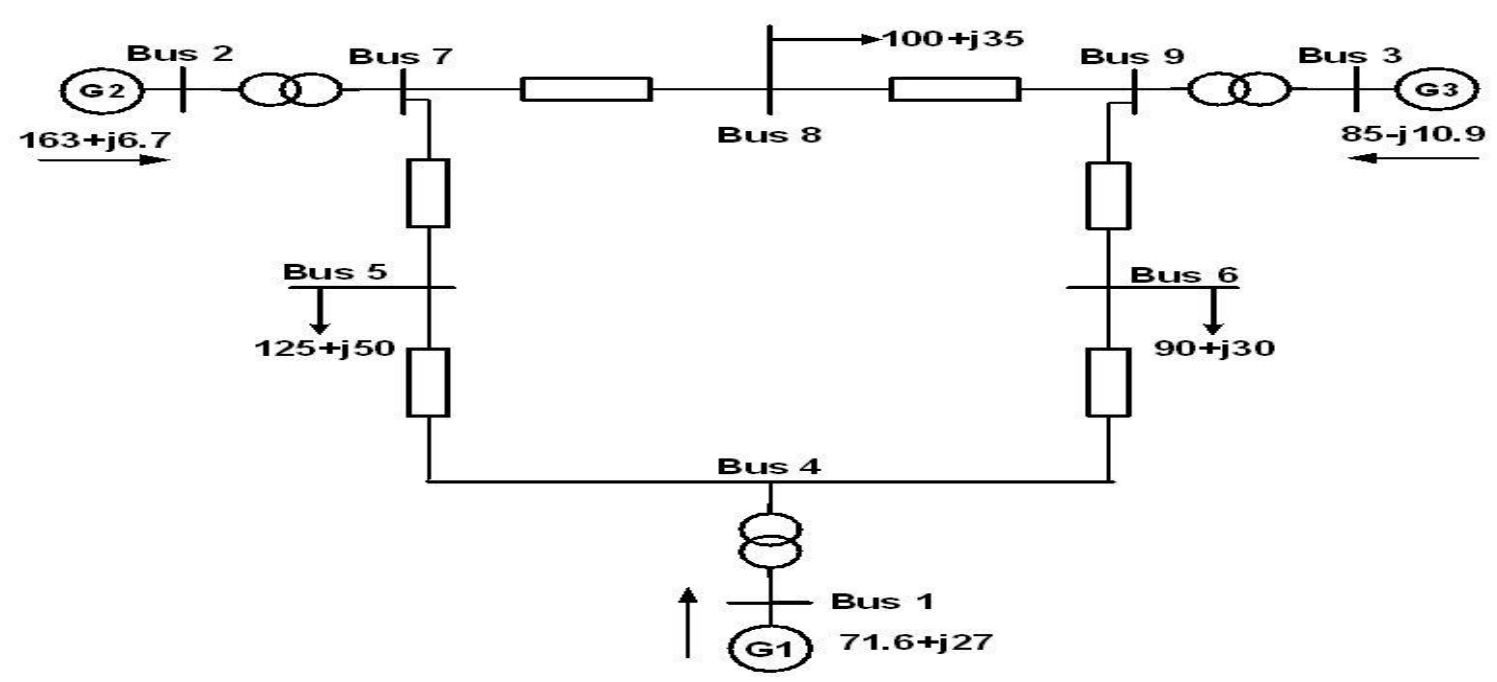

\section{SIMULATIONS}

Fig (2) - Schematic diagram of IEEE 9-bus system

The simulation is performed using the grid shown in Figure 2, the location of the PV is changed in each case. The test will be repeated three times (number of load buses) and in each case we will study the system and determine the THD. Finally, we will draw the relation between load percentages and THD. The load at each bus will be increased by certain percent from total connected load equal to PV penetration level. The effect of PV location and level of penetration on the value of the THD will be analyzed.

\section{A. Case 1:}

The load (100MW) at bus 8 , step increased by $5 \%$ till $25 \%$ from the total load connected to this bus. The PV is connected to bus $(8,6$, and 5) at different penetration level equal to the value of load increase and the results is shown in figure 3 , which shows the simulation results of max THD at all buses in this case. It is clear that, the THD is minimum when the PV system is connected at bus 6 , which is the minimum loading bus.

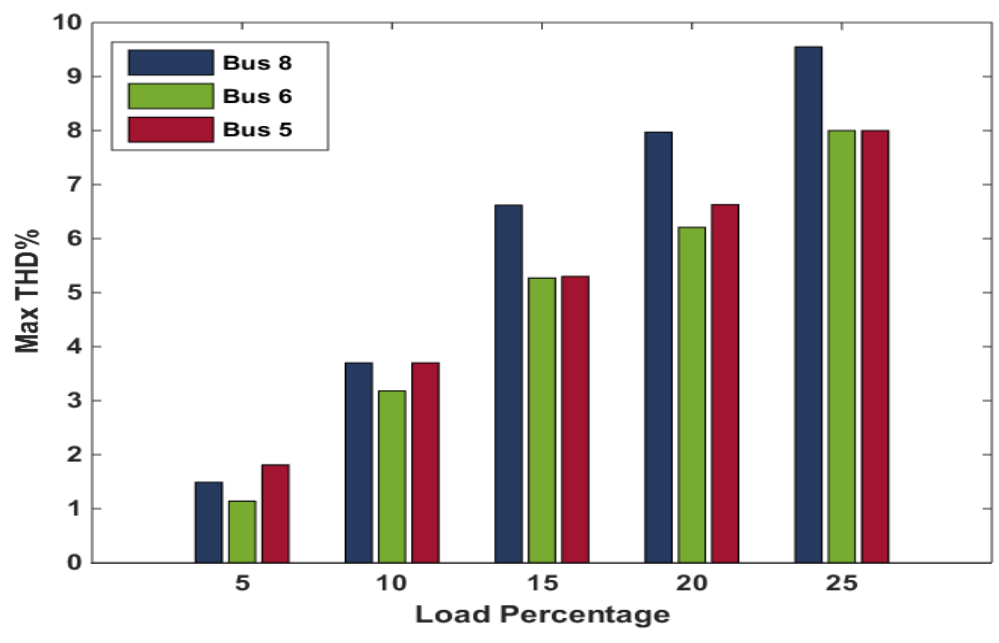

B. Case2:

Fig (3) - THD for load increasing at Bus 8

The load (90MW) at bus 6 , increased by the same way as case 1 and PV system is connected to bus $(8,6$, and 5$)$ at different penetration level equal to the value of increased load and the results is figure 4 . The result shows that, with load variation at bus 6 , the minimum THD is obtained when the PV system is connected at Bus 6, the same as case 1. 


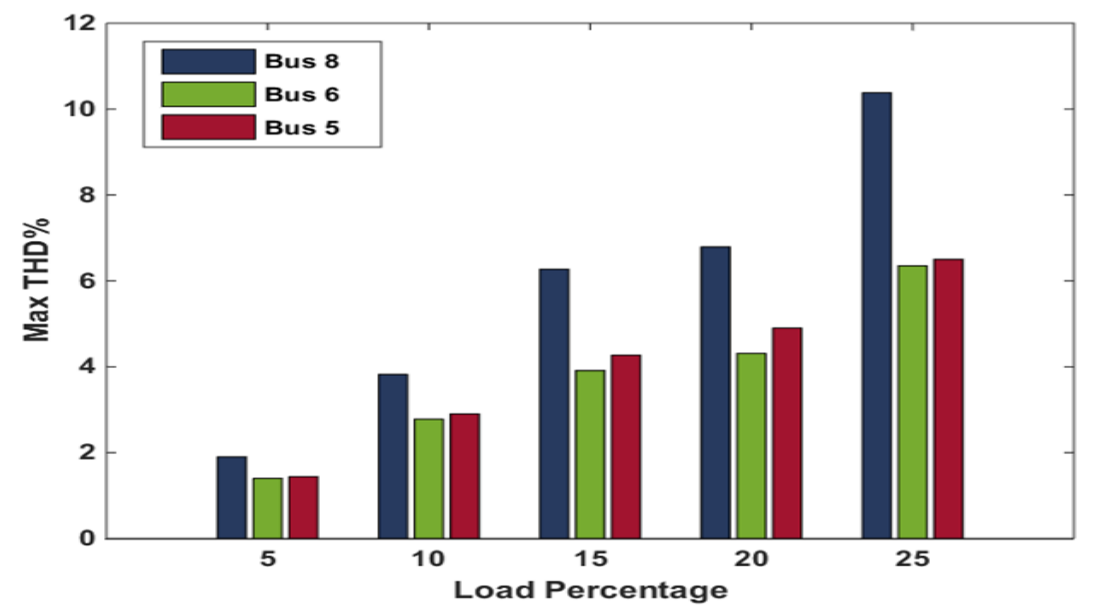

\section{Case3:}

Fig (4) - THD for load increasing at Bus 6

The load (125MW) at bus 5, increased by $5 \%$ till $20 \%$ from the total load connected to this bus. The PV system is connected to bus $(8,6$, and 5) at different penetration level equal to the value of increased load and the results is shown in figure 5. The result shows that, with load variation at bus 5, the corresponding minimum THD is obtained when PV system is connected at Bus 6 , the same as case 1 and 2.

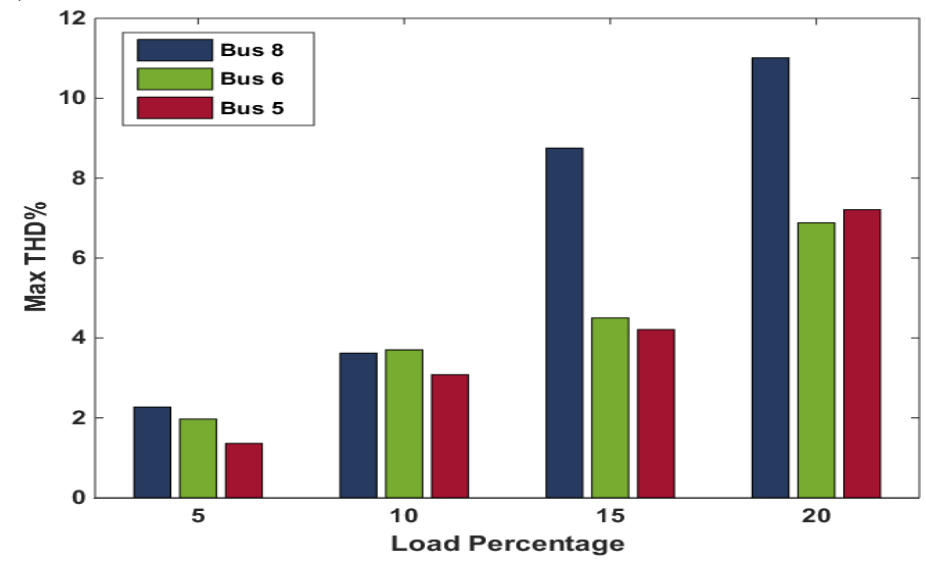

Fig (5) - THD for load increasing at Bus 5

From the simulation result, it is clear that the best location for the PV array system that gives minimum THD is at bus 6 . Bus 6 is minimum load bus. We will check if best location is affected by changing loading or generation in the next two cases.

\section{Case 4:}

We will replace load at bus 6 with load at bus 5 , where bus 5 will connect minimum load value and bus 6 will connect maximum load value. Then repeat case 3 , where the load at bus 5 increased by $5 \%$ till $25 \%$ from total load connected to this bus and connects PV at bus $(8,6$, and 5) at different penetration level equal to the value of increased load. The results is shown in figure 6 which show that, with exchange loads, the minimum THD is obtained when the PV system is connected at Bus 6 the same as case 1, 2 and 3. 


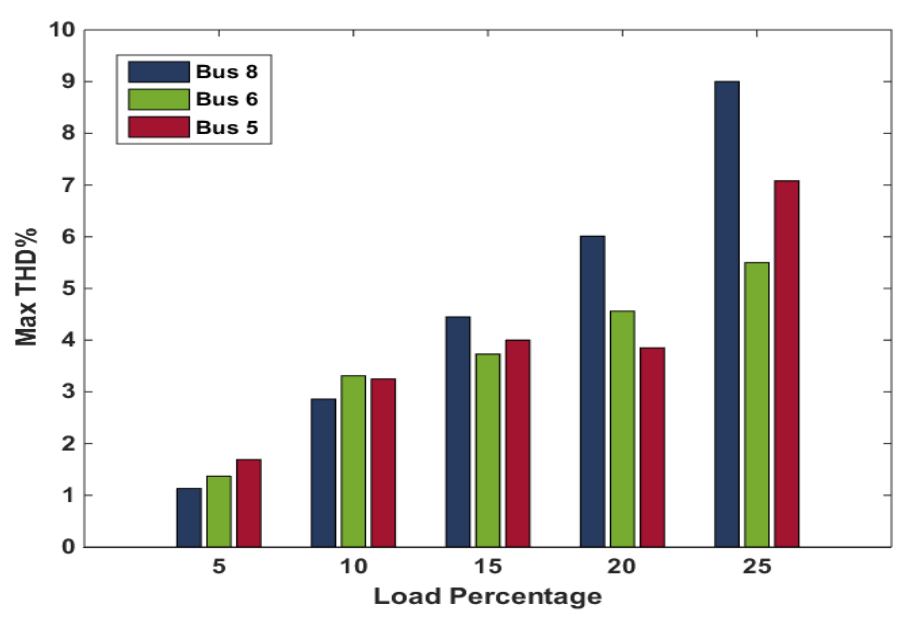

Fig (6) - THD after exchange load at bus 5 with load at bus 6

\section{E. Case 5:}

The generator at bus 1 will be replaced by the generator at bus 3 . Then repeat case 2 , where the load at bus 6 increased by 5\% till 25\% from the total load connected to this bus and connects PV to bus $(8,6$, and 5) at different penetration level equal to the value of increased load and the results is shown in figure 7 . The result shows that, with generator exchange, the minimum THD is obtained when the PV system is connected at Bus 6 , the same as case 1,2, 3,4 .

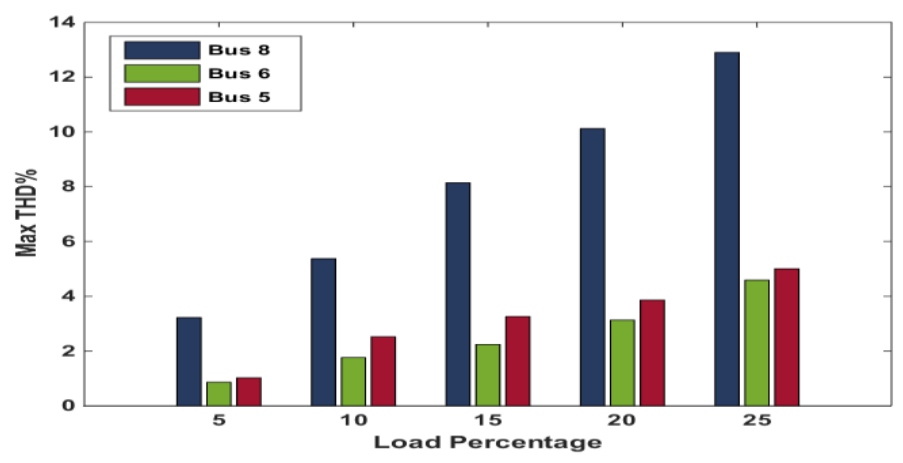

Fig (7) - THD after exchange generator at bus 1 with generator at bus 3

\section{CONCLUSION}

The inverter is one of the essential parts for any PV grid connected system. The inverters usually increase the harmonics in the grid. From the results it can be conclude: First, the THD increases with increasing the depth of penetration of the PV system. Second, for any power grid, there is a best location for the PV system to be connected to, which gives the minimum THD and in order to keep the THD within the recommended limits there is a maximum value for the penetration level of the PV array system. From case 1,2,3, it is clear that bus 6 is the best location that gives minimum THD, as recommended by IEEE Std. 519-1992. Since bus 6 is minimum load bus. We had two cases to check effect of loading and generation in best PV location. In case 4 after replace load in bus 6 with the largest load at bus 5 . We find that the best location does not change with increase load, so we can say that best PV location that gives minimum THD does not affected by load changing. In case 5 after replace generator in bus 1 with the generator at bus 3 . We find that the best location does not change with changing generation.

Then, the final conclusion is that for any grid topology there is:

1- A maximum level of PV system penetration, after which some means of harmonic mitigation should be added to the system.

2- There is a best location for each grid at which the PV system should be connected in order to minimize the THD.

\section{REFERENCES}


[1] Hui Zhang; Hongwei Zhou; Jing Ren; Weizeng Liu; Shaohua Ruan; Yongjun Gao, "ThreePhase Grid-Connected Photovoltaic System with SVPWM Current Controller," Proceedings Of IEEE 6th International Conference on Power Electronics and Motion Control (IPEMC), pp. 2161-2164, May, 2009.

[2] Satyaranjan Jena; B.Chitti Babu; S.R.Samantaray and Mohamayee Mohapatra, "Comparative Study Between Adaptive Hysteresis and SVPWM Current Control for Grid-connected Inverter System," Proceedings Of IEEE Students' Technology Symposium (TechSym), pp. 310-315, Jan., 2011.

[3] Yukai Liu, Zhijian Hu, Ziyong Zhang, Jianglei Suo, Kaibin Liang , “ Research on the Threephase Photovoltaic Grid-connected Control Strategy " Energy and Power Engineering, 2013, $5,31-35$

[4] M. G. Villalva, J. R. Gazoli, and E. R. Filho, "Comprehensive approach to modeling and simulation of photovoltaic arrays," IEEE Transactions on Power Electronics, Vol. 24, No. 5, pp. 1198-1208, May, 2009.

[5] Ahmed S. Khalifa and Ehab F. El-Saadany; "Control of three phase grid connected photovoltaic power systems," Proceedings Of IEEE 14th International Conference on Harmonics and Quality of Power (ICHQP), pp. 1-7, 2010.

[6] H. Haeberlin; L. Borgna; M. Kaempfer and U. Zwahlen, "New Test at Grid-Connected PV Inverters: Overview over Test Results and Measured Values of Total Efficiency ," 21th European Photovoltaic Solar Energy Conference, Dresden, Germany, Sept., 2006.

[7] Simeen. S. Mujawar , G. M. Karve , "Control of grid connected inverter system for sinusoidal current injection with improved performance " international journal of innovations in engineering research and technology, volume 1, issue 2 dec-2014

[8] Z. Yao, L. Xiao, J. M. Guerrero, "An improved control strategy for the three-phase gridconnected inverter," IET Renewable Power Generation, 2015.

[9] M. A. Elgendy, B. Zahawi, and D. J. Atkinson, "Comparison of directly connected and constant voltage controlled photovoltaic pumping systems," IEEE Trans. Sustain. Energy, vol. 1, no. 3, pp. 184-192, Oct. 2010.

[10] Ch.Mounika, Ch.Sampath Kumar, Shaik Khamuruddin, "Implementation of Sustainable DC Grid Connected PV System during Day \& Night “" international journal of innovative research in electrical, electronics, instrumentation and control engineering, vol. 2, issue 8 , august 2014

[11] P.R. Sharma, Rajesh Kr.Ahuja, Shakti Vashisth, Vaibhav Hudda, " Computation of Sensitive Node for IEEE- 14 Bus system Subjected to Load Variation". Vol. 2, Issue 6, June 2014.

[12] P.Vinoth Kumar1, D.Maheswari2,T.Nandha Kumar3, Power Quality Improvement for Grid Connected Photovoltaic System, Vol.2, No.2, Pages : 23-28 (2013), Special Issue of NCRTECE 2013 - Held during 8-9 February, 2013 in SMK Fomra Institute of Technology, OMR, Thaiyur, Kelambakkam,Chennai.

[13] Atul more,Abhimanyu Mane,Vivek Khandkhure,Anup Dakre, "Improving the Power Quality Performance for Distributed Power Generation", Vol. 1, Issue 1, July 2014.

[14] S. Sheik Mohammed, Modeling and Simulation of Photovoltaic module using MATLAB/Simulink. October 2011, Volume 2, No.5.

[15] Chandani M. Chovatia, Prof. Narayan P. Gupta, Prof. Preeti N. "Gupta. Power Quality Improvement in a PV Panel connected Grid System using Shunt Active Filter", Volume 2, Issue 4, August 2012.

[16] Masoud farhoodnea1, Azah mohamed, Hussain shareef, Hadi zayandehroodi . "Power Quality Analysis of Grid-Connected Photovoltaic Systems in Distribution Networks". ISSN 0033-2097, R. 89 NR 2a/2013.

5. Appendix

Table 1 Data of PV module from the datasheet.

\begin{tabular}{|l|c|c|c|c|c|}
\hline Maximum Power (Pmax) & $305 \mathrm{~W}$ & $\begin{array}{c}\text { Open-circuit voltage } \\
\text { (Voc) }\end{array}$ & $\mathbf{6 4 . 2 \mathrm { V }}$ & $\begin{array}{c}\text { Temperature coefficient of } \\
\text { Current (Isc) }\end{array}$ & $3.5 \mathrm{~mA} /{ }^{\circ} \mathrm{C}$ \\
\hline Voltage at Pmax (Vmp) & $\mathbf{5 4 . 7} \mathrm{V}$ & $\begin{array}{c}\text { Short-circuit current } \\
\text { (Isc) }\end{array}$ & $\mathbf{5 . 9 6} \mathrm{A}$ & $\begin{array}{c}\text { Temperature coefficient of } \\
\text { Voltage (Voc) }\end{array}$ & $-\mathbf{1 7 6 . 6} \mathrm{mV} /{ }^{\circ} \mathrm{C}$ \\
\hline Current at Pmax (Imp) & $\mathbf{5 . 5 8 \mathrm { A }}$ & Efficiency & $18.7 \%$ & Temperature coefficient of power & $-\mathbf{0 . 3 8 \%} /{ }^{\circ} \mathrm{C}$ \\
\hline
\end{tabular}

